Supplement of

\title{
Particle-bound reactive oxygen species (PB-ROS) emissions and forma- tion pathways in residential wood smoke under different combustion and aging conditions
}

Jun Zhou et al.

Correspondence to: Josef Dommen (josef.dommen@psi.ch)

The copyright of individual parts of the supplement might differ from the CC BY 4.0 License. 


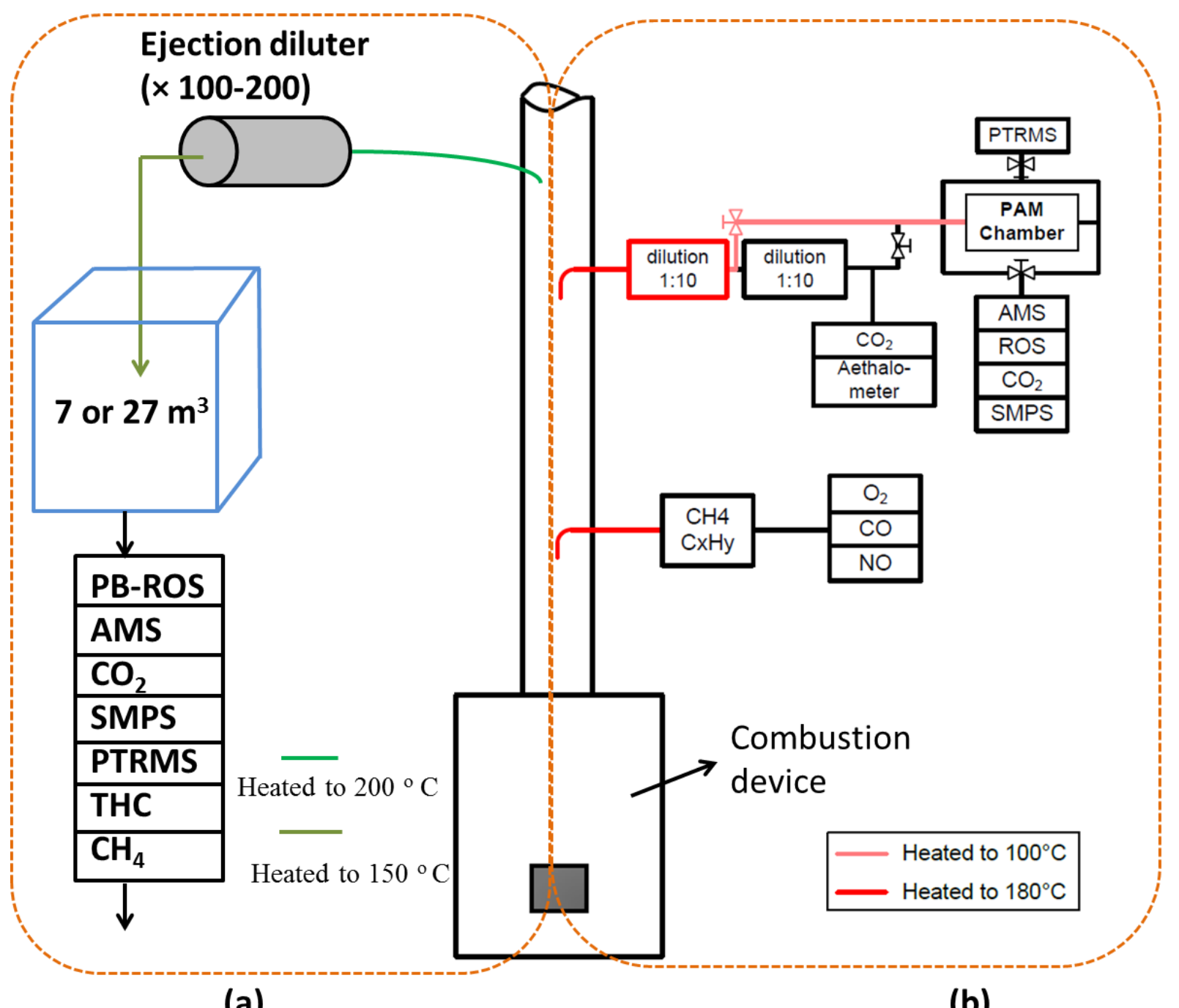

(a)

(b)

Figure S1. Schematic of wood combustion emissions aged by a) smog chamber (SC) and b) and potential aerosol mass (PAM) chamber. 
5

10
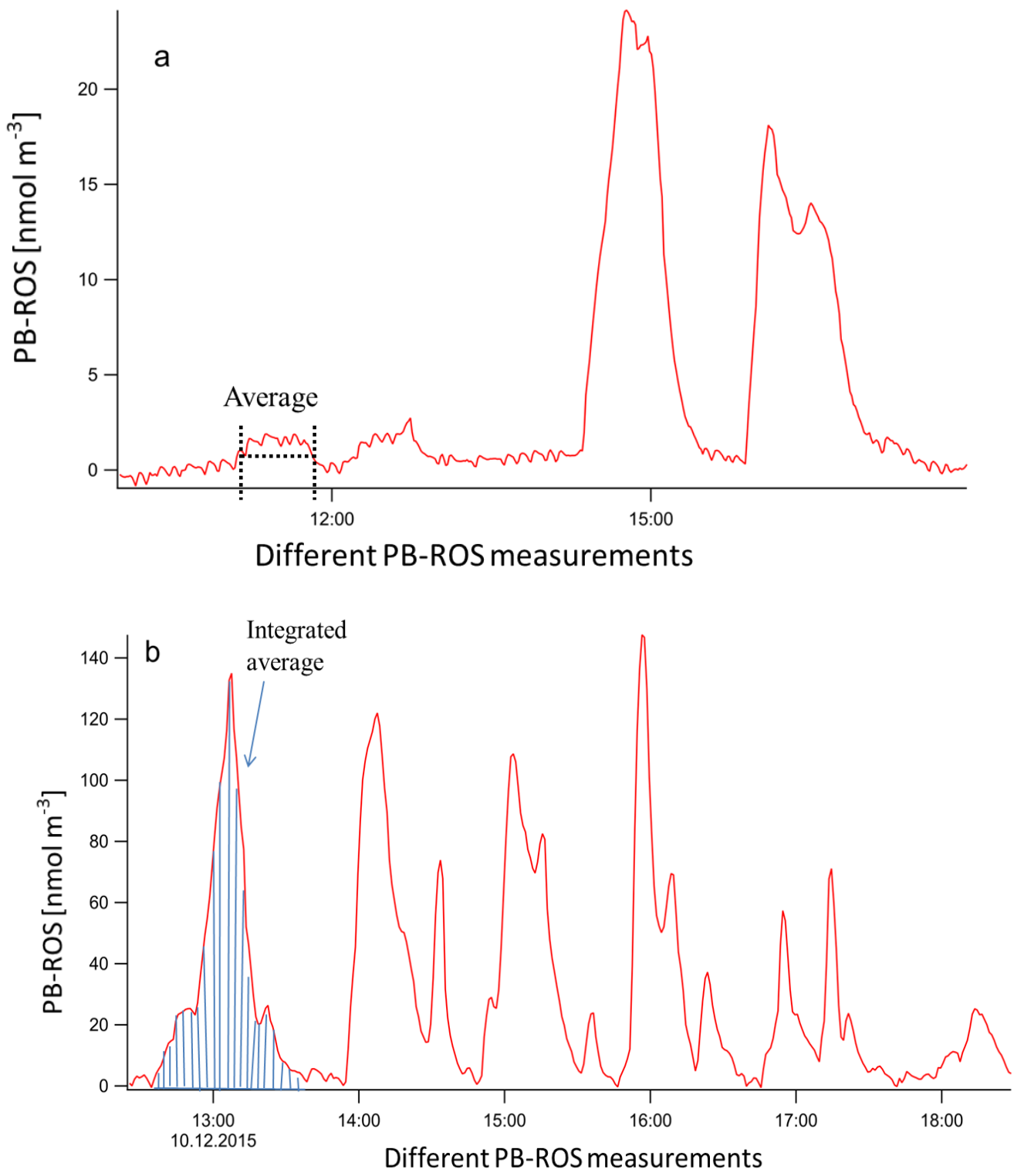

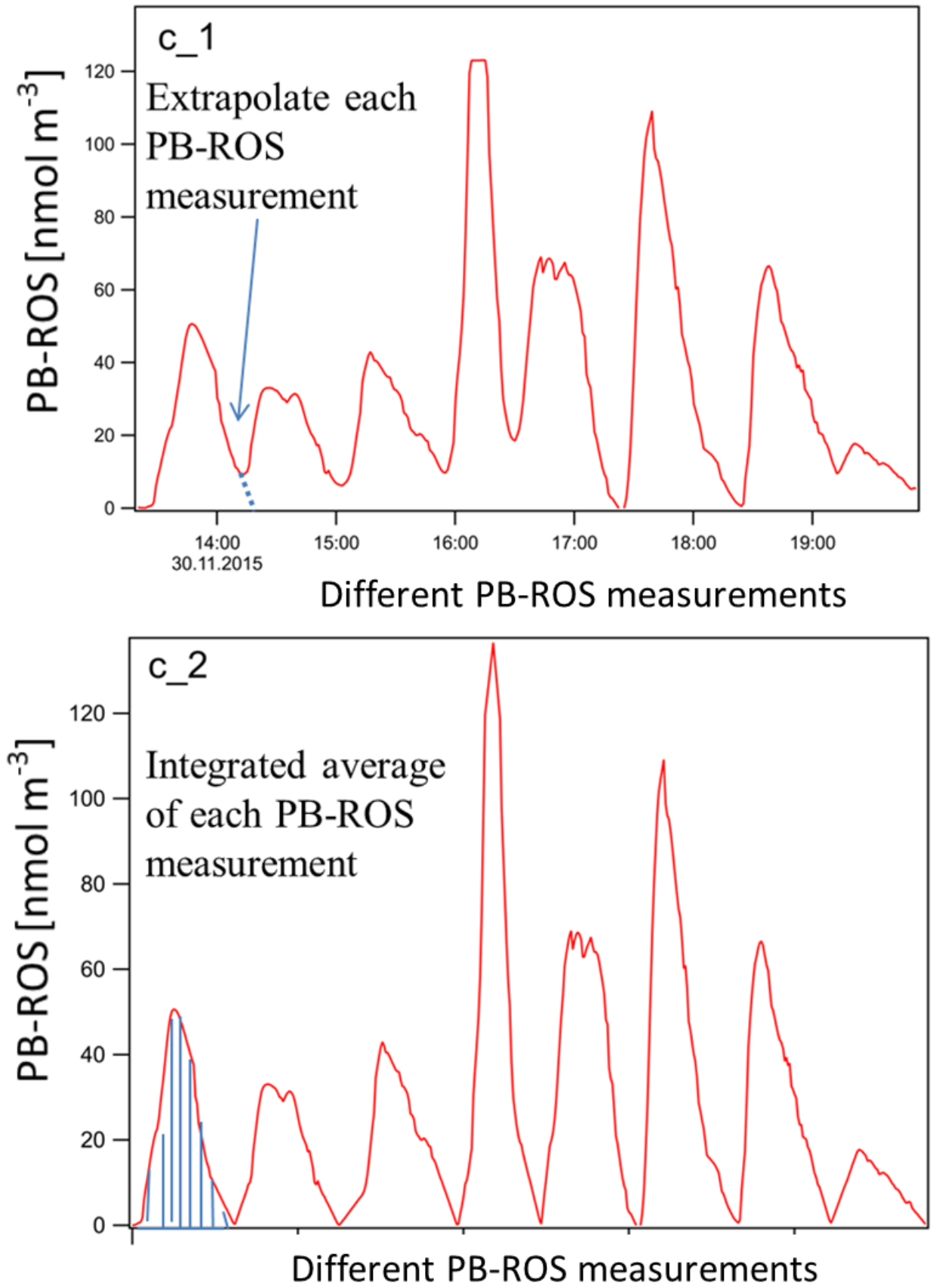

Figure S2 PB-ROS content calculation methods during different combustion conditions, a) average b) integrated average c) extrapolated for the experiments with no background measurements (c_1) and the integrated average (c_2) of those experiments. 


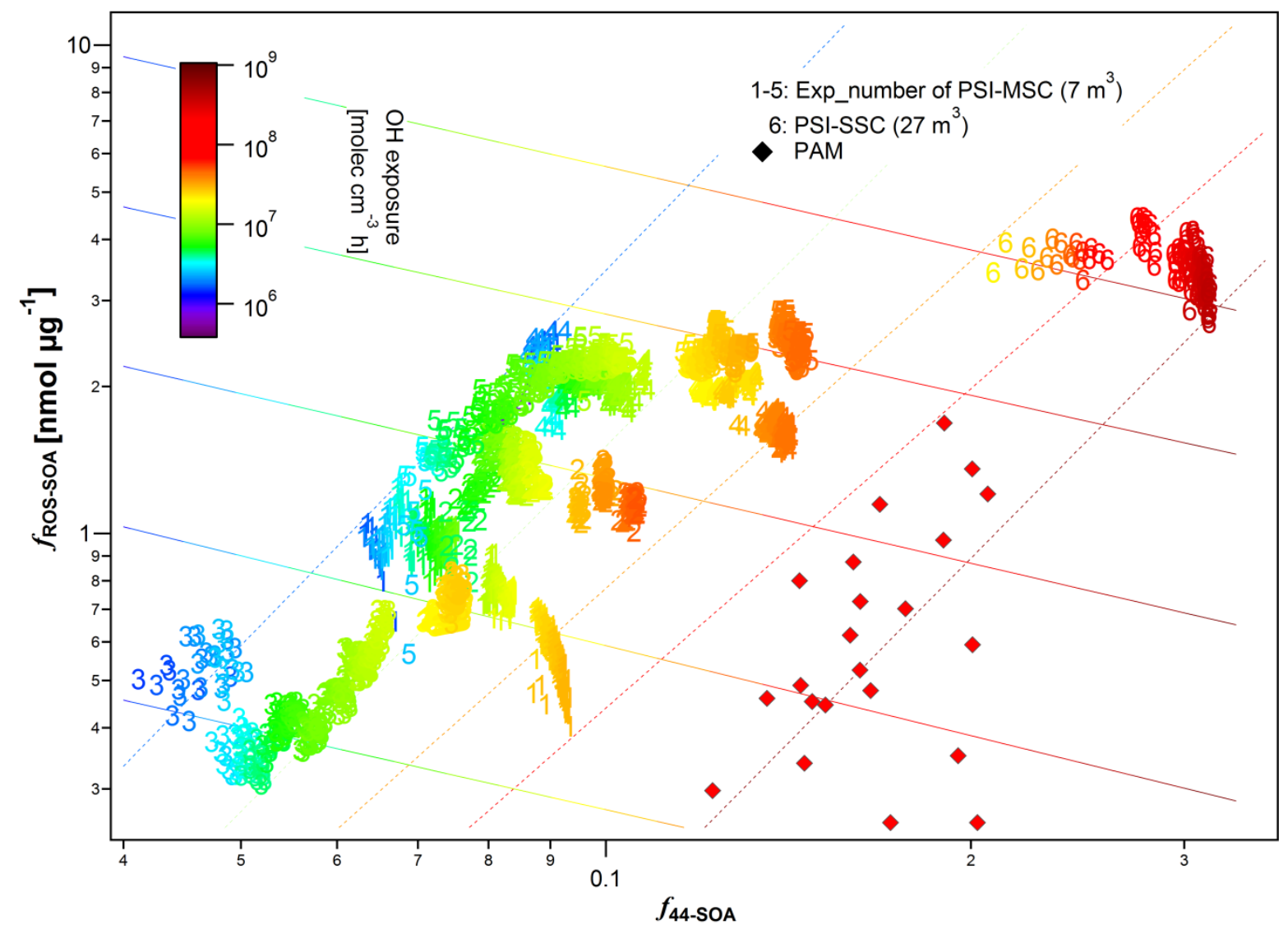

5 Figure S3: Variation of the fraction of ROS in SOA, $f_{\text {ROS-SOA }}$, with the fraction of $m / z 44$ in the secondary organic aerosol measured by the AMS ( $f_{44-\mathrm{SOA}}, \mathrm{x}$-axis) and the $\mathrm{OH}$ exposure estimated from the decay of $\mathrm{d} 9$-butanol measured by the PTR-ToF-MS (color code). Data are collected from two different smog chambers (SC) and from the PAM chamber. Dashed lines are isopleths of constant $\mathrm{OH}$ exposures, while solid lines are obtained by isolating the effect of $\mathrm{OH}$ exposure from the other variables. Numbers $1-5$ represent the sequence of the five $7-\mathrm{m}^{3} \mathrm{SC}$ experiments, Number 6 represents a single $27-\mathrm{m}^{3}$ SC experiment. 


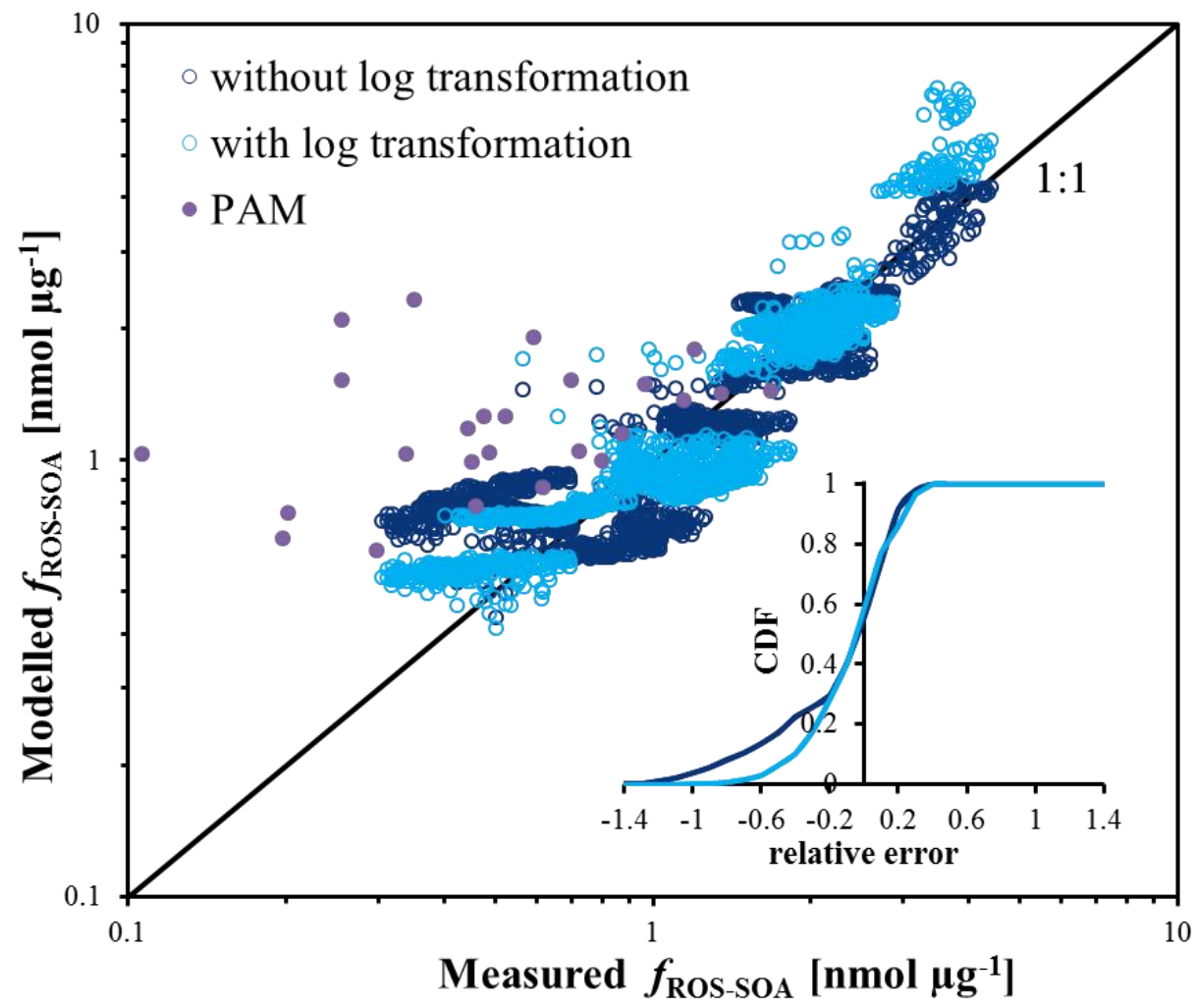

Figure S4: Comparison of the performance of two multiple regression models, with and without log-transformation of the data. The $f_{\text {ROS-SOA }}$ measured in the PAM is predicted using the same parameterization and results are displayed for comparison. The inset shows the cumulative density function (CDF) of the relative model residuals (measurements-model). 


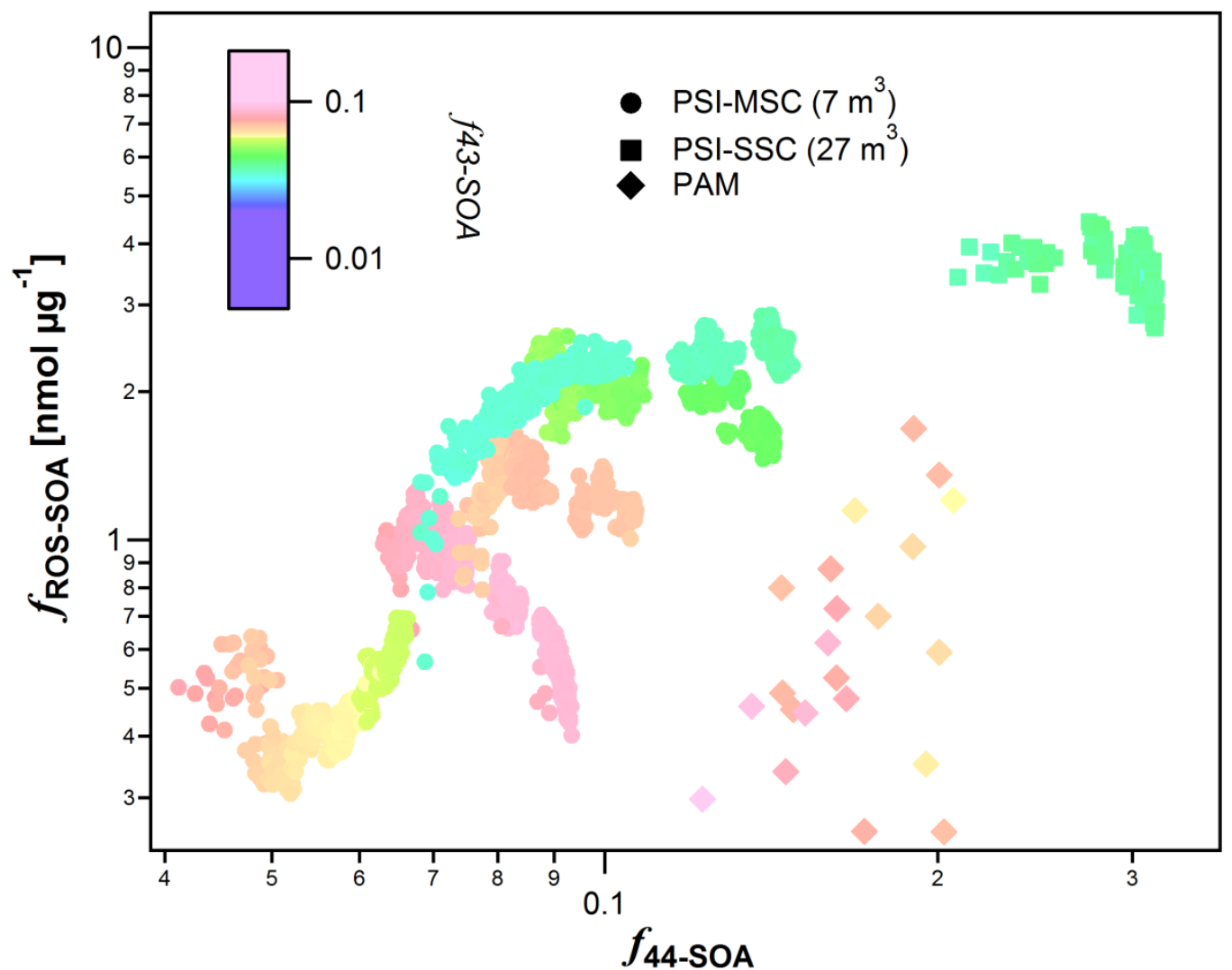

5 Figure S5: Variation of the fraction of ROS in SOA, $f_{\text {ROS-SOA }}$, with the fractions of $\mathrm{m} / \mathrm{z} 44$ and $\mathrm{m} / z$ in the secondary organic aerosol measured by the AMS $\left(f_{44-\text { SOA }}\right.$, x-axis and $f_{43-\mathrm{SOA}}$ color code). 